fication, whether modified for each frequency or not, is insufficient for many deaf people, and some speech synthesizing is required. With modern electronic engineering this kind of system demands no greater size for the hearing aid than the present amplifiers. Many other electronic devices are now available which only a large concern like the Health Department can develop for the benefit of the deaf. Perhaps therefore the Medical Research Council should initiate another report.

\footnotetext{
1 Committee on Electro-acoustics of Medical Research Council, Hearing Aids and Audiometers, Special Report Series No. 21. London, H.M.S.O., 1947.

2 Brooks, D. M., Hearing, 1971, 26, 302

3 Which?, February 1973, p. 38.

4 Trinder, E., Sound, 1972, 6, 62
}

\section{What Future for Computers?}

As experience has given doctors greater familiarity with the potential uses of computers in medicine, it has become clear that the question that needs to be answered is not what machines can do, but what it is worthwhile for them to do. Answers to both questions were suggested last week at a discussion meeting at the Royal Society, and as with so many problems in medicine there still seems to be a lot of research needed.

The big impact of computers and automation on clinical medicine has been in laboratories, which by the use of automated analysis have been able to cope with an annual postwar growth of $15-20 \%$ in requests for investigations on patients. The effect of the newer multi-channel machines has been that 20 tests can now be performed on a single specimen of blood more quickly and more cheaply than a single test done by bench methods, and many laboratories now run the full spectrum of investigations as a routine on every patient for whom any biochemical test is requested.

However, the development of high speed multi-channel machinery has, it seems, been a response more to the commercial attractions of potential markets in North America than to the needs of clinicians in Britain, while no-one seems concerned to design simple equipment suitable for the humid atmosphere and unpredictable electricity supplies found in many developing countries. Furthermore, the increased speed and accuracy of the biochemical estimations has not been parallelled by similar advances in techniques for transmitting information between the laboratory and the climician. There was obvious approval at the meeting for the view of one scientist that he was less concerned with the accuracy of his haemoglobin to two places of decimals than with the certainty that it was his blood sample that had been analysed.

A major problem for clinicians in the interpretation of the mass of data provided by automated analysis has been their unfamiliarity with statistical methods and concepts. Several examples were given at the meeting of the value of discriminant analysis in dealing with a number of variables none of which alone gave a conclusive answer to the diagnostic problem, and there seems little doubt that such techniques will become more widely used in the next few years. At the same time several research units are looking critically at the information sought about patients by traditional methods. When all the positive and negative data about patients attending a hypertension clinic are stored on computer records subsequent analysis should be able to identify which data were of clinical value and which were not, and this is being done at a number of units in Britain.

For the foreseeable future, however, there seems no doubt that the traditional written clinical record will remain in existence. Even in the highly developed computer-based record system in Stockholm the computer acts essentially as an expanded index to the typewritten case notes-though in practice the information available from the computer is all that is needed for most purposes and reference to the detailed notes is rarely necessary. This system is based on a reliable central population register, and certainly the ready acceptance by the Nordic countries of a personal 10 digit identification number given at birth has eliminated many of the problems encountered in Britain by record linkage systems.

Perhaps the greatest preiudice against automated medicine has been in the field of comouter diagnosis. Paradoxically, most of the technical difficulties have been in non-controversial areas such as chromosome analysis and screening of cervical smears, while more success has come in aspects of diagnosis reauiring clinical judgment. The effectiveness of computer aided diagnosis in acute abdominal pain has been shown convincingly at Leeds University, where the computer's rate of diagnostic error was only half that of the most experienced surgeon. This performance reflects the advantage that can be built into a comvuter if it has experience of hundreds of cases to rely on. Clinicians of the old school acquired an instinctive appreciation of diagnostic probabilities by their personal contact with large numbers of patients, suggested Dr. G. M. Bull at the end of the meeting, and he pointed out that this wealth of "clinical material" is not available nowadays. It seems likely that more use will be made in the future of comouter-based assessments of probabilities in clinical diagnosis, but as an adiunct to traditional techniques and not as a competitor or replacement.

A necessary corollary of the increasing role for computers in clinical medicine is that the new generation of doctors will need to acquire skills neglected by most of their teachers: familiarity with probability theory and simvle statistical analysis will be essential-as will an ability to type, since teaching doctors to use a typewriter keyboard is a better bet than teaching computers to read their handwriting. 